migration or recent male population bottlenecks. Our limited data set does not allow a robust test of the neutral hypothesis for variation between gorillas and chimpanzees.

Our data indicate that there are factors within the family Hominidae that limit levels of intraspecific polymorphism in this region of the $\mathrm{Y}$ chromosome relative to the rates of nucleotide substitution noted be-

1. Uchida, A. Trends Ecol. Evol. 11, 163-168 (1996).

2. Garner, K. J. \& Ryder, O. A. Mol. Phyl. Evol. 6, 39-48 (1996)

3. Tucker, P. K. \& Lundrigan, B. L. Phil. Trans. R. Soc. Lond. B 350, 221-227 (1995).

4. Hammer, M. F. Nature 378, 376-378 (1995).

5. Whitfield, L. S., Sulston, J. E. \& Goodfellow, P. N. Nature, 378, 379-380 (1995).

6. Dorit, R. L., Akashi, H. \& Gilbert, W. Science $\mathbf{2 6 8}$ 1183-1185 (1995). tween these species. This renders problematical the use of these data in establishing Y-chromosome divergence times.

Wes Burrows, Oliver A. Ryder

Center for Reproduction of Endangered Species,

Zoological Society of San Diego,

PO Box 551, San Diego,

California 92112-0551, USA

e-mail: oryder@jeeves.ucsd.edu

7. Fu, Y. \& Li, W. Science 272, 1356-1357 (1996).

8. Vigilant, L., Stoneking, M., Harpending, H., Hawkes, K. \& Wilson, A. C. Science 253, 1503-1507 (1991).

9. Hudson, R. R., Kreitman, M. \& Aguade, M. Genetics 116, 153-159 (1987)

10. Kocher, T. D. \& Wilson, A. C. in Evolution of Life: Fossils, Molecules and Culture (eds Osawa, $\mathrm{S}$. \& Honjo, T.) 391-413 (Springer, Tokyo, 1991).

\section{Biological activition of hydrogen}

SIR - Hydrogenases are enzymes that can reversibly split molecular hydrogen. Most hydrogen-activating enzymes contain both nickel and iron (termed $\mathrm{Ni} / \mathrm{Fe}$ hydrogenases), whereas others contain only iron (Fe hydrogenases). In $\mathrm{Ni} / \mathrm{Fe}$ hydrogenases, the nickel atom ${ }^{1}$ and a nearby iron atom ${ }^{2}$ form the site of hydrogen activation. Here we report that one carbon monoxide and two cyanide molecules are also part of this active site. The resulting $\mathrm{NiFeCO}(\mathrm{CN})_{2}$ prosthetic group is unprecedented in biological systems. The results may be useful for the design of cheap biomimetic hydrogen catalysts for water electrolysis and fuel cells.

Recently, we discovered ${ }^{3-5}$ that $\mathrm{Ni} / \mathrm{Fe}$ hydrogenases absorb intensely in the $2,150-1,850 \mathrm{~cm}^{-1}$ infrared spectral region, producing a distinct set of bands where no other proteins show absorption. The sensitivity of the absorption bands to changes in the active site indicated to us that the bands might arise from groups (metalbound diatomic molecules with a triple bond, or triatomic molecules containing two adjacent double bonds) located at the active site of the enzyme ${ }^{4}$. At the same time as these studies, the crystal structure at $2.85 \AA$ resolution ${ }^{2}$ of a $\mathrm{Ni} / \mathrm{Fe}$ hydrogenase (from the bacterium Desulfovibrio gigas) was reported. This structure has an iron atom located within $3 \AA$ of the nickel atom

Evidence for a low-spin iron ion, distinct from those with high-spin in the iron-sulphur clusters of the enzyme, had

\begin{tabular}{lccc}
\hline \multicolumn{3}{c}{ Infrared absorption bands for hydrogenase } \\
\hline Enzyme & Band 1 & Band 2 & Band 3 \\
Unlabelled & 2,093 & 2,083 & 1,945 \\
${ }^{15}$ N-enriched & 2,062 & 2,050 & 1,944 \\
Frequency shift & -31 & -33 & -1 \\
${ }^{13}$ C-enriched & 2,047 & 2,036 & 1,900 \\
Frequency shift & -46 & -47 & -45
\end{tabular}

Bands are in the $2,150-1,850 \mathrm{~cm}^{-1}$ spectral region (infrared); hydrogenase obtained from c. vinosum.

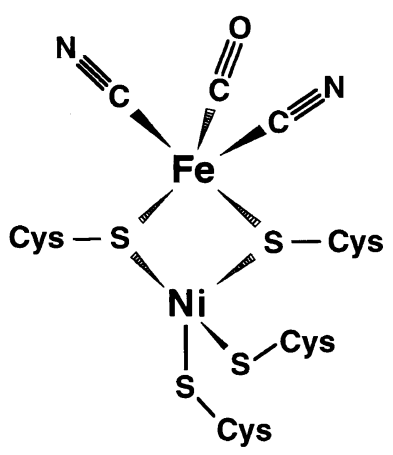

Model of the active site of $\mathrm{Ni} / \mathrm{Fe}$ hydrogenases (modified from ref. 2 on the basis of the present work). Assignment of the positions of $\mathrm{CO}$ and $\mathrm{CN}^{-}$is arbitrary.

come earlier from Mössbauer studies on the Chromatium vinosum enzyme ${ }^{6}$. Nickel and iron are connected by two bridging thiolate groups from cysteine residues. The nickel atom is further anchored to the protein by two more Cys-thiolate ligands. In addition, the electron-density map showed three distinct regions of electron density near the iron atom that were not attributable to protein ${ }^{2}$.

We have now identified the groups responsible for the three anomalous infrared bands using purified $C$. vinosum hydrogenase labelled with either ${ }^{13} \mathrm{C}$ or ${ }^{15} \mathrm{~N}$, by growth of the bacteria on appropriately enriched media. The greater mass of ${ }^{15} \mathrm{~N}$ (compared with natural ${ }^{14} \mathrm{~N}$ ) led to a shift to lower frequencies of two of the three infrared bands (see table), consistent with the stretching vibration of diatomic molecules containing one nitrogen atom. The greater mass of ${ }^{13} \mathrm{C}$ (compared with natural ${ }^{12} \mathrm{C}$ ) led to a shift to lower frequencies of all three bands (table). The data indicate the presence of two $\mathrm{CN}^{-}$groups and one $\mathrm{CO}$ bound to a metal. Suitable denaturation of the enzyme led to the release of about $0.5 \mathrm{~mol} \mathrm{CO}$ and $1.6 \mathrm{~mol}$ cyanide per mol enzyme, as determined by published procedures $^{7,8}$.

We conclude that the three nonprotein ligands of iron in the bimetallic active site of $\mathrm{Ni} / \mathrm{Fe}$ hydrogenases are one carbon monoxide and two cyanide groups (see figure). The resulting strong ligand field around the iron causes this ion to be low spin.

We further conclude that the lone lowspin iron ion observed in Mössbauer spectra of fully-reduced $C$. vinosum hydrogenase $^{6}$ is from the iron atom in the active site. None of the groups detected in the unlabelled enzyme was exchangeable with added ${ }^{13} \mathrm{CN}^{-}$or ${ }^{13} \mathrm{CO}$. The findings are in line with recent observations that the electron density of the non-protein ligands to iron hint at diatomic molecules ${ }^{9}$ deeply buried in the active-site cavity.

$\mathrm{Ni} / \mathrm{Fe}$ hydrogenases are among the oldest enzymes ( 3.8 billion years old), demonstrating that early life forms had developed an effective way to activate molecular hydrogen at ambient temperature and $\mathrm{pH}$. Interestingly, infrared bands similar to those in $\mathrm{Ni} / \mathrm{Fe}$ hydrogenases have also been discovered in two Fe hydrogenases ${ }^{5}$, suggesting a common active-site architecture for all metalcontaining hydrogenases.

The involvement of a Ni/Fe binuclear active site containing $\mathrm{CN}^{-}$and $\mathrm{CO}$ ligands comes as a surprise. Suitable model compounds incorporating these features have not yet been synthesized or tested. We anticipate that our results will lead to new avenues of enquiry into the development of efficient, cheap and stable hydrogen catalysts for the photovoltaic production of hydrogen by electrolysis of water, or for development of fuel cells, as alternatives to fossil fuels and nuclear energy.

\section{Randolph P. Happe \\ Winfried Roseboom \\ Antonio J. Pierik}

Simon P. J. Albracht

E.C. Slater Institute, Biochemistry/FS,

University of Amsterdam,

Plantage Muidergracht 12,

NL-1018 TV Amsterdam, The Netherlands

e-mail: a311siem@chem.uva.nl

Kimberly A. Bagley

Department of Chemistry,

State University College of New York at Buffalo,

Buffalo, New York 14222, USA

1. Albracht, S. P. J. Biochim. Biophys. Acta 1188, 167-204 (1994).

2. Volbeda, A. et al. Nature 373, 580-587 (1995).

3. Bagley, K. A. et al. Biochemistry 33, 9229-9236 (1994).

4. Bagley, K. A., Duin, E. C., Roseboom, W., Albracht, S. P. J. \& Woodruff, W. H. Biochemistry 34, 5527-5535 (1995).

5. Van der Spek, T. M. et al. Eur. J. Biochem. 237 629-634 (1996).

6. Surerus, K. K. et al. Biochemistry 33, 4980-4993 (1994)

7. Bonam, D., Murrell, S. A. \& Ludden, P. W. J. Bacteriol. 159, 693-699 (1984).

8. Nagashima, S. Anal. Chem. Acta 99, 197-201 (1978).

9. Fontecilla-Camps, J. C. J. Biol. Inorg. Chem. 1, 91-98 (1996). 